\title{
The economic approach to designing anticorruption institutions
}

\author{
Viktor Molokanov ${ }^{1 *}$, Elena Malysheva ${ }^{2}$,Ekaterina Chumakova ${ }^{3}$, Vadim Yakovenko $^{4}$ and Andrey Zelensky ${ }^{5}$ \\ ${ }^{1}$ Volgograd Institute of management - branch of The Russian Presidential Academy of National Economy and Public \\ Administration, 8 Gagarin street, Volgograd, Russia, vikmol@inbox.ru \\ ${ }^{2}$ Volgograd Institute of management - branch of The Russian Presidential Academy of National Economy and Public \\ Administration, 8 Gagarin street, Volgograd, Russia, decanatec@vlgr.ranepa.ru \\ ${ }^{3}$ Volgograd Institute of management - branch of The Russian Presidential Academy of National Economy and Public \\ Administration, 8 Gagarin street, Volgograd, Russia, chumakova-ea@vlgr.ranepa.ru \\ ${ }^{4}$ Volgograd Institute of management - branch of The Russian Presidential Academy of National Economy and Public \\ Administration, 8 Gagarin street, Volgograd, Russia, yakovenko-vv@, vlgr.ranepa.ru \\ ${ }^{5}$ Volgograd Institute of management - branch of The Russian Presidential Academy of National Economy and Public \\ Administration, 8 Gagarin street, Volgograd, Russia, zelensky-ag@vlgr.ranepa.ru
}

\begin{abstract}
Contemporary economic analysis of corrupt behaviour requires practical consideration of the issues concerning projecting of social anti-corruption institutions. The economic science has accumulated sufficient practical experience of institutional construction in society, for instance approaches provided by K. Sunstein's and E. Ostrom. The requirement of reasonability in managing economic interactions makes the society refuse from the dichotomy of market (anarchical, spontaneous) and non-market (hierarchical) institutions. The same tendency can be observed in arranging anti-corruption struggle in state management. Both approaches - aimed at creating fixed vertical hierarchy as well as at creating competition at the lowest bureaucratic level - are inappropriate. That is why anticorruption institutions arranging should be based on economic models of rational criminal and citizens involvement in law enforcement activity. These models enable to harmonize state dirigisme related to the state management ex ante with basic provision of laissez-faire doctrine - personal motives of people's behaviour. Standard economic supply and demand model has shown inelasticity of corruption crimes supply in Russia. Non-price determinants (cultural norms, "tabu") seem to be more significant in motivating corruption behaviour than price determinants (seriousness and probability of punishment). Economic characteristics of elasticity and inelasticity of supply and demand in the model of involvement into law enforcement activity enable to create strategy of developing social anti-corruption institutions.
\end{abstract}

\section{Introduction}

In mainstream economic theory there are two approaches explaining allocation of economic goods. Goods in the market of production factors can be allocated either by means of the market itself or by the state. The economic science offers theories explaining social choice of allocation of world rare goods.

However, this institutional polarization (either market or the state) typical for mainstream science is subject to more and more critics by scientific society. Ideologically approved constructions under pressure of experience accumulated by humanity have been replaced with opportunist approach. If the truth can exist only as "useful delusion" rather than reflection of "objective reality" the person's intellectual activity must be directed at transformation of experience itself (reality) rather than systematic perfection of it in all spheres of human life [1].

The most severe criticism against polarization of market and non-market institutions is mostly directed at blurring of line between anarchic and hierarchical orders.

One of the most significant works in this respect is the book "Economic Institutes of Capitalism" by $\mathrm{O}$ Williamson [2], in which the author discloses a convincing theory of effective opportunity management in market economy. The idea that making a deal requires appropriate structure of management enabled to prepare the most significant construction of market economy of anarchic order. The spontaneous order of the market covers only part of all possible deals in the economy. The other part but not the least requires creating longterm sustained structures of managing the deals with established hierarchical relations where the state can take its place as well. Uncertainty of the future makes

* Corresponding author: vikmol@inbox.ru 
entrepreneurial activity highly-risky if it is connected with rarely taken opportunities related to specific assets. The practice of overcoming this uncertainty demonstrates high relevance of law as the most significant state institute.

Another significant work postulating opportunism approach to managing economy is the work by E. Ostrom "Governing the Commons. The Evolution of Institutions for Collective Action" [3]. In this paper the author reinterprets one more dogma of mainstream economic theory, so called tragedy of commons. The tragedy of commons reveals significance of property rights in fulfilling the key goal of economic theory effective usage of rare resources. Any resource without property title is subject to non-productive usage. In case of tragedy of commons the standard recommendation is privatization or nationalization of the resource. On the basis of multiple examples E. Ostrom demonstrated that the system of common property can be effective. Irrigation systems of Spain and California, cattle grazing and timber cutting in the mountains of Switzerland and Japan, fishing in Turkish Alania are the examples of successful cooperation of close communities having common economic activity, possessing rare, scarce resources without private or state property. The book gives description of the rules of constructing institutions enabling effective allocation of scarce resources in conditions of communal, common property, shows the consequences of managing common resources without following agreed rules. Wide implementing of the mechanisms of private and public partnership into Russian practice of municipal management is the reflection of ideas described by E. Ostrom [4]. The problems and perspectives of such reforming of municipal management are touched upon in many articles devoted to this subject [5].

Strong arguments against ideologization of economic science can also be found in R. Thaler and K. Sunstein's works [6]. R. Thaler, a Nobel laureate on Economics in 2017, suggested a curious construction - "libertarian paternalism" [7]. This oxymoron discloses Thaler's opposing the ideologeme that the public paternalism is always an evil. As R. Thaler and K. Sunstein write the liberal economy advocates' prejudices base on "false assumption and two misconceptions" [8]. The false assumption implies that proponents of free market economy argue that every person knows better than others what is the most preferable for him. It is obvious that the right choice is possible only in case of having full information, possessing appropriate competences and having enough experience. The belief that every person knows everything in every sphere of human existence characterizes quite naïve researcher's position.

The first misconception implies that there can be unconditioned choice. The theoretics of behavioural economics call conditioned choice the framing effect. And if it is impossible to isolate human choice from the context why not use conscious constructing of social institutes to make the human choice more conditioned, based on knowledge and experience.

The second misconception implies assurance in forced character of any paternalism. It's the reason why
Thaler's paternalism is called libertarian as it doesn't imply any bans or enforcement. The state can and must construct institutes orienting the human to make "the right choice" although he can make "the wrong choice" as well.

The above-represented review of worldviews against extra ideologization of approaches to managing economy doesn't support both extreme statist as well as anti-statist views. Opportunism as the principle of achieving effectiveness in organization of social economy enables to release from ideology the process of developing every day instruments for reforming modern society.

As it was already highlighted there is not only one way of allocating resources in the society. Resources can be allocated by means of the market system or political system. Moreover, allocation mechanism of the political system is not subordinate or optional in relation to the market allocation. Over half of the national income practically in all developed countries including the USA is allocated through the public structures. That is why the effectiveness of the political market is in focus of researchers-economists. One of the main problems determining efficiency of the state impact on the economy is corruption.

\section{Problem Statement}

The economist's standard approach to the problems of corruption is the analysis of the phenomenon according to the algorithm described in agency theories. The logics of this algorithm is simple. The Consumer (the Principal) concede some of its functions to the Agent. The Agent is understood as rational subject isolated from society and making decisions if it is necessary to leap to opportunistic behaviour or not, basing only on balance between benefits and losses. The Agent leaps to opportunistic behaviour only in case when his benefit from it more significant than punishment inncured [9]. Legislative power is the Agent of voters. The Supreme executive power (the Government) is the Agent of a legislative body. Ordinary officials can be agents of the ministers and heads of governmental agencies. Corrupt actions of public authorities (such as Parliament and Government) are naturally limited by periodicity of voting cycle. It enables to limit time and size of corruption. The institute of political reputation and derived from it requirement of publicity of the authority effectively prevent corruption at top authority levels. Lower officials' corruption requires another approach to analysis.

If scientists-criminologists try to explain criminality by means of unique psychological and physiological traits of criminals economists consider these properties as given and they believe that criminals as any other economic agents react to incentives and make rational choice of the best available alternative [10]. Thus, economists-theorists researching criminality by means of economic approach base their research on "the common assumption of individual rational behaviour" according to which the criminal action is committed only when the general benefit from it taking into consideration 
sanctions and other costs higher than from legal alternatives. Criminal's behaviour in economic theory is mostly considered as ordinary human behaviour rather than deviant behaviour with uncommon motivation while criminality is considered as a common trade similar to doctor's or teacher's profession [11].

\section{Research Questions}

During the research it was supposed to get answers to the following questions:

1. Is it possible to combine public enforcement and motivation of citizens' behaviour while working out anti-corruption policy?

2. What economic models can be used in analysis of corruption behaviour?

3. How does the standard model of demand and supply disclose peculiarities of corruption services market?

\section{Purpose of the Study}

The lack of attention on the part of Russian legal science to the opportunities of economic theory determined the goal of the research which implies development of theoretic approach enabling to combine public enforcement institutes with personal motivation of citizens to analysis of corruption behaviour. In order to reach this goal it necessary to fulfil the following objectives:

1. to reveal inefficiency of taking only administrative anti-corruption measures;

2. to present economic models enabling to consider both citizens' inner motivation as well as administrative factor;

3. to demonstrate how demand and supply model discloses the character of corrupt services market.

\section{Research Methods}

Within the present research classic general scientific methods of research and processing information were used such as: comparison and analogy, analysis and synthesis, induction and deduction, geographic method, comparative statics.

\section{Findings}

The analysis of low level corruption requires formalized model of criminal behaviour. Institutional economic theory has got the model of rational criminal [12]. Let's suppose that $\mathrm{x}$ is the number of definite crimes committed, i/e/ the number of times when the criminal takes possession of a definite sum of money. Then $y$ is the criminal's compensation for committed crimes. The function of criminals compensation will increase with increasing $x$, i.e. with increasing number of crimes $y=y(x)$. Let's introduce the function of criminal's punishment $\mathrm{f}$. The function of punishment will increase with increasing number of committed crimes as well $\mathrm{f}=\mathrm{f}(\mathrm{x})$. Punishment for crimes is of probabilistic nature, that is why we will introduce p-parameter in the model as probability of punishment for committed crimes. The function of punishment probability also increases in case of increasing $x(p=p(x))$. The rational criminal choses the optimal number of definite crimes being conducted by the classic principle of maximizing net advantage $\partial(\mathrm{y}(\mathrm{x})-\mathrm{p}(\mathrm{x}) \mathrm{f}(\mathrm{x})) / \partial \mathrm{x}=0$.

If $\mathrm{x}$ is the number of definite crimes committed by one individual then $X=\sum$ w is the total number of crimes committed in a society. According to the model of rational criminal the number of crimes in the society is inversely related with increasing probability and severity of punishment. Now we can draw the supply curve of definite crimes in a definite society (see figure 1).

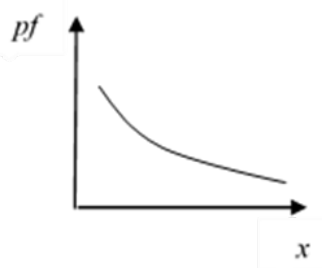

Fig. 1. Crime supply.

This curve enables to formulate the first law of sustaining: the more the probability to be caught or the severer the punishment the fewer the number of committed crimes. The slope of crime supply curve enables to come down to the quality conclusion about the character of criminality including corrupt activity. The more elastic is the crime supply curve the stronger its connection with the price of these crimes the brighter is the dependance described in the first law of sustaining. And vice versa, the less elastic is the crime supply the weaker manifestation has the abovementioned law (see figure 2).

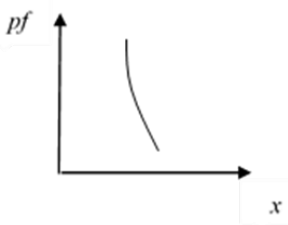

Fig. 2. Non-elastic crime supply.

Anti-corruption fighting in public management in RF has been significantly strengthened for the last years. There are institutes that were created to prevent negative tendences of corruption character that certainly led to the increasing probability of being caught by law enforcement agencies, increasing penalties and sentences for corruption crimes. However, there cannot be observed qualitative shift in decreasing the number of committed corruption crimes. One of the possible explanations of this situation can be non-elasticity of corruption crimes demand in Russia. And if it is so then the factors described in the model of rational criminal (probability and severity of punishment) don't play significant part in motivating corrupt officials. There occur the phenomenon that economist call non-price factors of supply and in this case public moral principles, cultural norms, "tabu", the quality of education are the factors determining the character of criminal activity of 
Russian corrupt officials. The embeddedness and wide spread of corruption make us to assume that they cannot develop without creating definite institutional environment, asserts famous scientist and popular former official of the federal level G.A. Satarov [13].

There can be distinguished three models of making decisions by bureaucrats: fragmentarily sequential hierarchical and disorganized [14]. In fragmentarily sequential model decisions are made at several autonomous stages. Applicants request is divided into parts and every part undergoes its special procedure of confirmation. In hierarchical model (traditional bureaucracy) decisions made at the lower level can be reconsidered at any moment at the higher level of management. These models differ by incentives of corrupt behaviour of lower level official. Honest official at the higher level of the bureaucratic ladder will stimulate corruption at lower levels in fragmentarily sequential model and decrease corruption in hierarchical model. And vice versa dishonest official at the higher level of the bureaucratic ladder stimulates corruption in hierarchical models and discourages corruption at lower levels of in fragmentarily sequential model. Disorganized model is typical for bureaucratic structures, where criteria of decision making are spontaneous and the structure of management is subject to constant changes.

In fighting against corruption it is commonly recommended to change the structure of decision making in order to decrease authority of the level involved in corruption activity. And thus as routine corruption is mass at the lowest level than the most populist decision will be shifting authority to the officials of the higher level of the hierarchy. The lowest level officials just accept the requests of the applicants while the final decisions are made by the superior. However, centralization doesn't lead to decreasing of corruption. The corruption simply shifts from lower to upper levels. If the lower level official does not make decision and transfers requests to the upper level without processing the volume of superior's work can significantly increase. It will influence the quality and first of all the quantity of decisions made and in this case the bribe becomes the institute that makes the superior's work easier.

Rejecting of centralization of management stimulates corruption at lower levels. The standard reaction of the economist fighting against routine corruption is creating competition among officials. However, advantages from bureaucratic competition often do not compensate advantages from specialization and monopolization of managerial functions. Consequently, reforms aimed at shifting officials' authority to different levels of management appear to be counterproductive. Approaches related to centralization and decentralization of management appeared to be senseless in the sphere of anti-corruption fighting[15].

If corruption has been deeply established in Russian culture then anti-corruption fighting should be concentrated on breaking norms approving corruption activity. This can be realized only by means of wide involvement of the population of the country in anti- corruption activity. The economic science can provide its theory of population involvement to fight against criminal activity.

Undoubtedly for an ordinary person any help rendered to law enforcement agencies causes costs: spending private time, taking efforts, waiving personal comfort and safety. Let's consider the model with the vertical axe OY showing costs related to providing help to law enforcement agencies and horizontal axe OX showing the share of population ready to incur such costs. There is no need to prove inverse relation between these parameters. (see Figure 3)

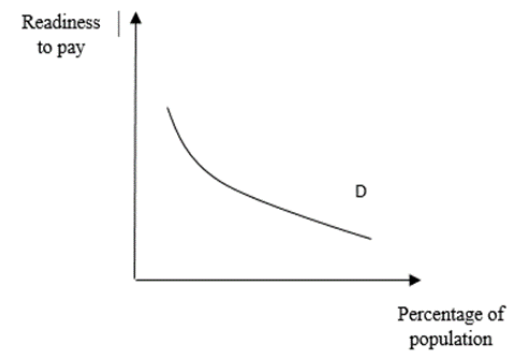

Fig. 3. Readiness to pay for participation in law enforcement.

The cost value of every person's involvement in fighting against criminality decreases due to psychological effect of "comfort behaviour" with growth of the number of people providing help to law enforcement agencies. (see Figure 4). The growth of popularity of a definite action among citizens decreases involvement costs.

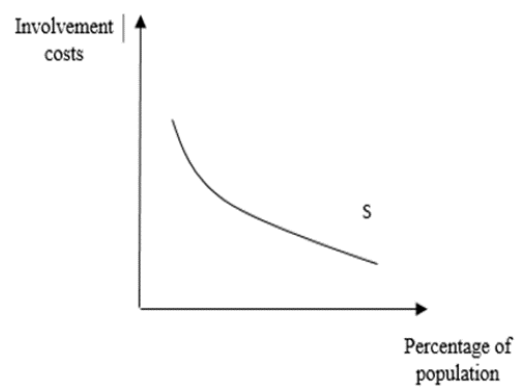

Fig. 4. Costs of public involvement in law enforcement activity.

The share of citizens that will provide help to law enforcement agencies in anti-corruption fighting in this model is determined by intersecting of the demand curve that implies «readiness to pay» (Figure 3) and supply curve that implies «readiness to incur costs» (Figure4). As the result we get the standard set of instruments used by economists - the demand and supply model in the market of citizens involvement in law enforcement activity (see Figure 5) 


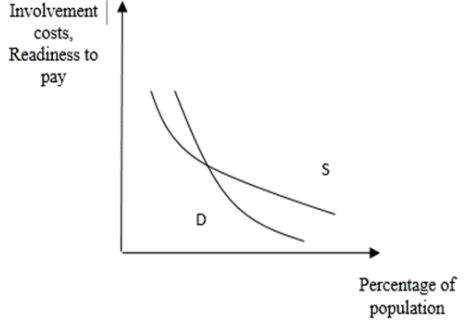

Fig. 5. Equilibrium in the market of involvement in law enforcement activity.

At that there can be two states of the market : a) supply curve $\mathrm{S}$ is more elastic than demand curve $\mathrm{D}$ (see Figure 5); b) demand curve D is more elastic than supply curve $\mathrm{S}$ (see Figure 6).

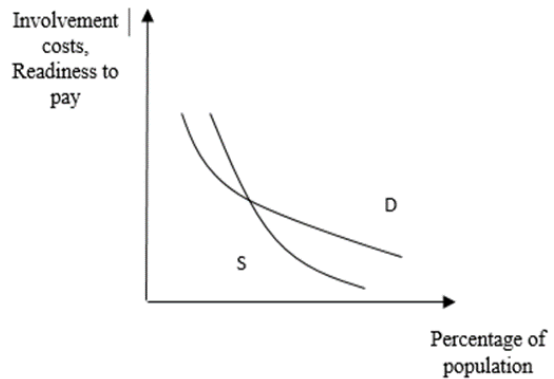

Fig. 6. Equilibrium in economy of scale.

Figure 5 illustrates the opportunity of the only equilibrium in full conformity with the theory of demand and supply. If in the market demand is higher than supply it leads to deficiency People are ready to pay for participation in law enforcement activity more than it is required by social costs of involvement, that leads to the growth of the number of participants in this market by the level of the intersection point. If in the market the supply exceeds demand then there is a surplus of involvement in law enforcement activity and the share of population involved in this market will decrease by the level of intersection point because social costs of involvement in law enforcement activity are higher than the human desire to incur such costs.

From the perspective of developing legal norms the situation described in Figure 6 seems to be more interesting. Here the surplus is created to the left from the point of intersection and the deficiency is formed in the right part. The surplus stimulates decreasing participation in law enforcement activity and consequently the equilibrium will tend to reach zero share of involvement while the deficiency stimulates the growth of participation in law enforcement activity and consequently the equilibrium will tend to reach $100 \%$ of involvement. In Figure 6 there are two equilibriums and both of them appear at the intersection of demand and supply curves. Such situation occurs when social approvement of participation in law enforcement activity sharply decreases involvement costs. This dynamics of costs is interpreted by the economist as the economy of scale.

\section{Conclusion}

The analysis of the market of public involvement in law enforcement activity by means of supply and demand curves determines the algorithm of fighting against corruption directed at breaking cultural norms approving corrupt behaviour. The strategy aimed at increasing the share of the population participating in law enforcement requires creating deficiency states both to the left and to the right of the intersection of demand and supply curves. It means that at first it is necessary to provide conditions described in the left part of the figure 5 and then reflecting the situation in the right part of the figure 6.

Realizing managerial decisions in modern conditions it is necessary to avoid polarization of approaches typical of theoretical opposition of market and public institutes. Reaching economic effectiveness including one in public reforming requires using more opportunistic methods combining both hierarchical as well as anarchic structures of management. Fighting against corruption by means of shift of power at different levels of managerial hierarchy is non-productive in theory as well as in practice. It is impossible to create competition in the market of bureaucratic services due to significant benefits from specialization and monopolization of managerial functions. Character of Russian corruption enables to come down to the conclusion about its nonprice nature. In case the probability and seriousness of the punishment for corruption crimes are not determining it is necessary to focus on reviewing accepted in society cultural norms approving corruption behaviour. It requires in its turn wide public involvement in law enforcement activity. Supply and demand model in the market of public involvement in law enforcement activity enables to develop growth strategy of the population involved in fighting against corruption

\section{References}

1 D.V. Semenov, Contemporary Scientist 4, 234-245 (2017)

2 O. Williamson, The Economic institutions of capitalism. Firms, Markets, Relational Contracting. (Saint Petersburg, Russia: Lenizdat; CEV Press, 1996)

3 E. Ostrom, Governing the commons: the evolution of institutions for collective action (Moscow, Russia: IRISEN, Thought, 2010)

4 S. I., Shishkin, \& M. A. Lavrik, Siberian Legal Bulletin 3, 30-36 (2018)

5 U.A. Aparina, \& D.A. Obozny, Transport Industry in Russia 2, 82-87 (2019)

6 R. Thaler, \& C. Sunstein, Nudge: Improving Decisions about Health, Wealth, and Happiness. (Moscow, Russia: Mann \& Ferber, 2017)

7 R.I. Kapelyushnikov, Aroung Behavioural Economics: a Few Comments about Rationality and Irrationality (Moscow, Russia: Publishing House of Higher School of Economics, 2018).

8 R.I. Kapelyushnikov, Behavioural Economics and New Patternalism. (Moscow, Russia: Publishing House of Higher School of Economics, 2013) 
9 Yu. I. Budovec, \& K.N. Lebedev, Basics of the Theory of Agents (Krasnodar, Russia: Publishing House Scientific and Research Institute of the Economy of the South Federal Region, 2019)

10 M.I. Levin, \& E.V. Pokatovich, Economics and Mathematical Methods 48(1), 44-55 (2012)

11 A. Bystryakov, \& N. Epifanova, State Service 6, 6265 (2016)

12 P. Cooter, \& T. Ulen, Law \& Economics (Moscow, Russia: Publishing House «Business» RANEPA, 2018)

13 G.A. Satarov, Russian Corruption: Level, Structure, Dynamics. Tests of Sociological Analysis. (Moscow, Russia: Foundation «Liberal Mission», 2013)

14 M.I. Levin, E.A. Levina, \& E.V. Pokatovich, Lections on Corruption Economics (Moscow, Russia: Publishing House of Higher School of Economics, 2011)

15 M.I. Levin, \& G.A. Satarov, Issues of Economics, 10, 4-29 (2012) 